\title{
Equilibrium and kinetics behavior of oil spill process onto synthesized nano-activated carbon
}

\author{
M. F. Elkady ${ }^{1,2, ~ *, ~ M o h a m e d ~ H u s s i e n ~}{ }^{3}$, Reham Abou-rady $^{3}$ \\ ${ }^{1}$ Chemical and Petrochemical Engineering Department, Egypt-Japan University of Science and Technology, New Borg El-Arab City, \\ Alexandria, Egypt \\ ${ }^{2}$ Fabrication Technology Department, Advanced Technology and New Materials and Research Institute (ATNMRI), City of Scientific Research \\ and Technological Applications, Alexandria, Egypt \\ ${ }^{3}$ Chemical Engineering Department, Faculty of Engineering, Alexandria, Egypt
}

Email address:

marwa.f.elkady@gmail.com (M. F. Elkady)

\section{To cite this article:}

M. F. Elkady, Mohamed Hussien, Reham Abou-rady. Equilibrium and Kinetics Behavior of Oil Spill Process onto Synthesized Nano-Activated Carbon. American Journal of Applied Chemistry. Special Issue: Nano-technology for Environmental Aspects. Vol. 3, No. 3-1, 2015 , pp. 22-30. doi: 10.11648/j.ajac.s.2015030301.14

\begin{abstract}
Oil spills were removed from polluted wastewater using synthetic nano-activated carbon that prepared through the alkaline activation of water hyacinth roots followed by zinc chloride treatment prior to its carbonization. The prepared nano-activated carbon attains high oil sorption capacity of $28.31 \mathrm{~g}$ oil $/ \mathrm{g}$ sorbent and no water pickup. The SEM examination of the prepared activated carbon investigates its spherical morphological structure with average diameter of $60 \mathrm{~nm}$. The different processing parameters affecting on the oil sorption onto the prepared nano-activated carbon were optimized. The maximum oil sorption capacity of $30.2 \mathrm{~g}$ oil $/ \mathrm{g}$ activated carbon has been recorded after $60 \mathrm{~min}$ sorption time using $10 \mathrm{~g}$ from the prepared nano-activated carbon at initial oil film thickness of $1 \mathrm{~mm}$. The oil sorption data recorded at equilibrium conditions have been analyzed using the linear forms of Langmuir, Freundlich, Temkin and Dubinin-Radushkevich (D-R) isotherm models and the applicability of these isotherm equations to the sorption system was compared by judging the correlation coefficients, $\mathrm{R}^{2}$. It was established that the equilibrium isotherm models applicability follows the order of: Freundlich> Langmuir> Dubinin-Radushkevich for the oil sorption onto activated carbon. Accordingly, the oil sorption process at equilibrium may be described mainly using both Freundlich and Langmuir isotherms. These results give prediction that the oil sorption process takes place onto nano-activated carbon as mono-layer coverage with some degree of heterogeneity. The kinetics of the oil sorption process was modeled using four kinetic models namely pseudo first-order, pseudo second-order, Elovich, and intraparticle diffusion kinetic models. The pseudo second-order model yielded the highest $\mathrm{R}^{2}$ value of 0.9933 . So, the kinetics of the oil sorption process onto the prepared nano-activated carbon may be described as second-order, which reveals that the main oil adsorption mechanism is probably chemisorption reaction.
\end{abstract}

Keywords: Nano-Activated Carbon, Oil Spills, Sorption Isotherms, Kinetic Modeling

\section{Introduction}

During the past decades there has been a significant increase in accidental oil spill in the aquatic environments. In the meantime the development of offshore petroleum operation has been considered the largest in the world in 1991 [1]. Each year, an average of 14 million gallons of oil from more than 10,000 accidental spills, are discharged into fresh water and salt water environments. Oil transportation and offshore oil exploitation as well as storage facilities can cause such problems. In addition, oil spills from tanker loading and offloading operations, pipeline ruptures, and other sources pose serious threats to the aquatic environment including fisheries and wildlife. Oil spill in marine freshwater is still a major environmental hazard. When oil is spilled into a marine environment, it is subjected to several processes including spreading, diffusion, evaporation, dissolution, photolysis biodegradation, and formation of water-oil emulsions [2]. The three dominating processes that cause changes in oil characteristics over time are spreading, evaporation, and 
emulsification. Spreading of oil on the sea surface reduces its thickness, while evaporation increases density and viscosity. The emulsification process significantly increases the viscosity of spilled oil and its density. All these, in turn, influence the oil properties and the related measurements. These oil spills on water or on land are a major concern in every country of the world. Such spills not only represent a loss of oil but also often have a major negative effect on natural flora and fauna and on human health. Besides, massive marine oil spills have occurred frequently and resulted in a great deal of damage to the marine, coastal and terrestrial habitats, economic impacts on fisheries, mariculture, and tourism, and loss of energy source. Therefore, it is necessary to develop a new technology for recovering the spilled oil to be recycled [3].

Physical, chemical, and biological processes can be used to recover/remove the oil or to destroy it in-situ. Skimmers, booms, and the use of sorbent materials are used to physically remove oil from the polluted water. In-situ burning, dispersing agents and solidifiers are used to chemically clean up oil. Adding biological agents is considered a biological method for removing the oil spill [4]. The main limitations of some of these techniques are their high cost and inefficient trace level sorption [5]. Most of the dispersants are often inflammable and can also cause health hazards to the operators and potential damage to fowl, fish, and marine mammals. They can also lead to fouling of shorelines and contamination of drinking water sources [6].

Among these methods that utilized for oil decontamination from a water surface, sorption technique widely assists in high-quality treated effluent. Sorbents are insoluble materials or mixtures of materials used to recover liquids through the sorption process. To be useful in combating oil spills, sorbents need to be both oleophilic (oil-attracting) and hydrophobic (water-repellent). Sorbents to be used on water should be able to sorb large amount of oil without sinking [7]. Activated carbon and exfoliated graphite are high effective materials for the removal of spill oil from sea water [8]. There are three major classes of oil sorbent materials, namely, inorganic mineral products, organic natural sorbents, and organic synthetic sorbents. The hydrophobicity, the surface area, and the capillarity of these sorbent materials are the major determining factors when choosing the best sorbent for oils and other hydrocarbons. In a majority of the sorbents there exists a continuous phase on which sorption takes place by hydrophobic interaction and a capillary region in which sorption occurs by capillary action and, perhaps, hydrophobic interaction [9]. At present, most of the commercially available oil sorbents are organic synthetic products such as polypropylene (PP) and polyurethane. However, they are non-biodegradable and can be difficult to deal with after use. Various natural sorbents such as rice straw, corn cob, peat moss, cotton, cotton grass, kapok, and water hyacinth have been studied for complete removal of spilled oil. These agricultural products and residues are inexpensive and available locally. Some are waste materials and hence their reuse will result in savings in disposal fee.
Water hyacinth (Eichhornia crassipes) is a floating, invasive non-native plant commonly encountered as dense mats in freshwater habitats; it may be considered a member of the pickerelweed family. It has attracted significant attention as the world's worst invasive aquatic plant due to its extremely rapid proliferation and congest growth, presenting serious challenges in navigation, irrigation, and power generation. Attempts to control the weed have proved to be costly with minimum results. However, the same plant has demonstrated an amazing ability to absorb many toxic wastes from aquatic environments. Availability in large quantities, high biosorption capacity, renewability, and low cost determine the extent to which biosorbents can be adapted technologically [10].

Activated carbons are unique and versatile adsorbents. Their adsorbent properties are essentially attributed to their large interparticulate surface area, universal adsorption effect, high adsorption capacity, a high degree of surface reactivity, and a favorable pore size which makes the internal surface accessible and enhances the adsorption rate. The most widely used activated carbons have a surface area of about 800 to $1500 \mathrm{~m}^{2 /} \mathrm{g}$. This surface area is contained predominantly within micropores which have effective diameter less than 2 $\mathrm{nm}$. A particulate of active carbon is made up of a complex network of pores that have been classified into: micropores (diam. $<2 \mathrm{~nm}$ ), mesopores (diam. between 2 and $50 \mathrm{~nm}$ ), and macropores (diam. $>50 \mathrm{~nm}$ ). Most of the adsorption process on active carbons takes place in micropores and only small amount in mesopores, the macropores acting only as conduits for the passage of the adsorbate into the interior mesopores and the micropores surface. The pore size distribution in a given carbon depends on the type of the raw material and the method and conditions under which the carbon has been prepared [11]. Activated carbon can be made from a variety of precursor materials such as coal, wood, coconut shell, etc. by some form of activation process. More recently interests have been generated in the preparation of activated carbon using agricultural by-products and unwanted, harmful plants as precursor materials [12]. Water hyacinth plant is considered a serious threat to the aquatic environment. The production of activated carbon from water hyacinth has potential economic and environmental impacts [13].

This study aims to achieve two positive effects with regards to the environmental safety management. First, consumption such harmful waste plant as adsorbent materials to be utilized in oil spill adsorption process that can get rid of its spread over the water areas, which causes substantial problems. On the other hand, oil spill on water surfaces is considered a great environmental problem and there is an increasing interest in limiting the spread of such liquid hydrocarbons in the environment, especially marine areas. Accordingly, nano-activated carbon has been extracted from the water hyacinth and tested for oil spill process. The different factors affecting the oil sorption process onto synthesized nano-activated carbon will be optimized using batch technique. The equilibrium and adsorption kinetics experimental data for oil spill onto the prepared activated 
carbon were theoretically modeled.

\section{Experimental}

\subsection{Materials and Chemicals}

Raw water hyacinth was collected from Alexandria Canal and washed with water to remove the dust then its two segments of roots and shoots were separated mechanically. The root segments were dried and grinded at specific particle size. The main composition the water hyacinth species were indicated at table (1).

Table 1. Average biomass composition of water hyacinth

\begin{tabular}{ll}
\hline Components & \% Composition \\
\hline Lignin & 17 \\
Cellulose & 60 \\
Hemicellulose & 8 \\
Ash & 12 \\
Nitrogen & 03 \\
\hline
\end{tabular}

The chemicals used for activated carbon preparation and oil sorption process were hexane (C6H14, El Gomhoria company), hydrochloric acid (HCL, El Nasr Pharmaceutical Company), sodium hydroxide ( $\mathrm{NaOH}$, Chemajet Chemical Company), phosphoric acid (H3PO4, Lab Chemical Trading Company, $85 \%$ ), and zinc chloride $\left(\mathrm{ZnCL}_{2}\right.$, Riedel-De HAEN AG,SEELZE, HANOVER, Germany).

\subsection{Synthesis of Nano-Activated Carbon from Water Hyacinth}

$5 \mathrm{~g}$ of dried water hyacinths roots were chemically treated with $50 \mathrm{ml} 1 \mathrm{M} \mathrm{NaOH}$ and nixed for 4 hours at the room temperature. After completeness the chemical modification process, the powder materials were separated and dried at $60^{\circ}$ C. the yielded powder were further chemically activated using $50 \%$ zinc chloride solution under heating at $60^{\circ} \mathrm{C}$ for 6hours. The activated powder materials were then carbonized at 600 ${ }^{\circ} \mathrm{C}$ for two hours at the muffle furnace under nitrogen atmosphere. The produced activated carbon was examined using Scanning Electron Microscope (SEM-JEOL JSM6360 LA, Japan) to investigate its morphological structure.

\subsection{Kinetic and Equilibrium Behaviors of Oil Adsorption Process onto Nano-Activated Carbon}

In order to describe the equilibrium and kinetic of oil sorption process onto nano-activated carbon, the batch technique was utilized to monitor the effect of contact time and material dosage. A specific weight of the prepared nano-activated carbon was immobilized onto $5 \mathrm{~cm} \times 5 \mathrm{~cm}$ polypropylene pad then this pad was spread over the surface of $500 \mathrm{ml}$ artificial sea water composed from distilled water contains $3.5 \%$ sodium chloride. A predetermined thickness of oil layer was poured onto the artificial sea water as polluting agents. The adsorbent material was shaken with oil polluted sea water for different intervals at determined temperatures. After the mixing period, the pad was separated and drained for $5 \mathrm{~min}$. the oil and water adsorbed by the nano-activated carbon was determined through piston squeezing. The water adsorbed by the nano-activated carbon was determined by centrifugation (ASTM D-1696-91) [14]. The amount of oil adsorbed was determined through subtracting the amount of water adsorbed from the total amount adsorbed by the material. Then the percentage of oil adsorbed and the oil sorption capacity per gram from nano-activated carbon were calculated. The influence of contact time and material dosage at the oil sorption process from sea water onto nano-activted carbon will be monitored. These experimental data will be modeled using various equilibrium and kinetic models.

\section{Results and Discussion}

\subsection{The Synthesized Nano-Activated Carbon}

In order to investigate the morphological structure of the prepared nano-activated carbon, the SEM imaging of the material was illustrated at Figure (1). It was indicated that the material was prepared in spherical morphological structure with average particle diameters equal to $60 \mathrm{~nm}$. Moreover, the image indicated large porosity of the prepared material.

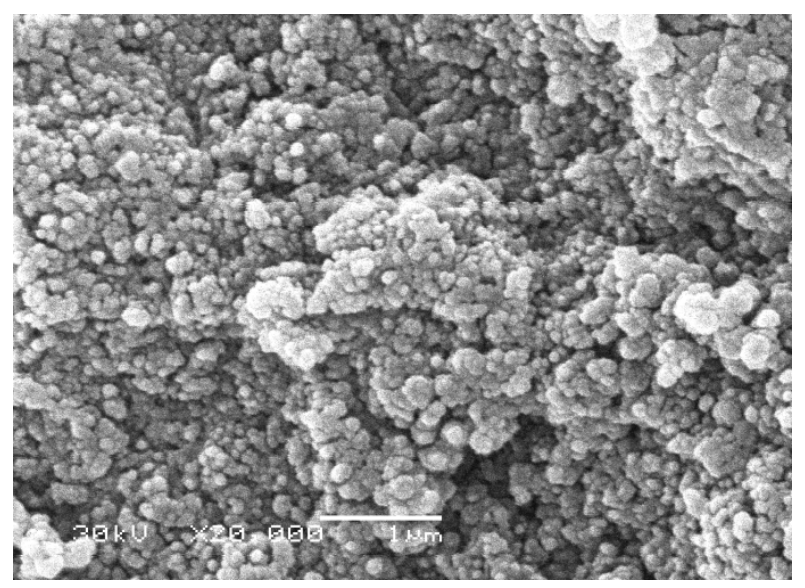

Figure (1). SEM image of prepared nano-activated carbon

\subsection{Kinetic Behavior of Oil Adsorption Process onto Nano-Activated Carbon}

In order to determine the kinetic behavior of the oil adsorption process onto the prepared nano-activated carbon the influence of the contact time was optimized.

\subsubsection{Effect of Contact Time on the Oil Adsorption Process}

The effect of sorption time on the adsorption capacity of oil onto the prepared Nano-activated carbon sorbent material was investigated in figure (2). The oil adsorption capacity onto the nano-activated carbon was increased with increasing the sorption time, until it reaches a maximum value at $60 \mathrm{~min}$, and then decreased until nearly constant values irrespective of the sorption time. Based on these results, 60 min was taken as the equilibrium time at the adsorption process. The rate of percent oil removal is higher in the process beginning due to a larger surface area of the adsorbent material being available for the adsorption of oil, there is a fast diffusion onto the external 
material surface which is followed by fast pore diffusion into the intraparticle matrix up to attain the equilibrium at $60 \mathrm{~min}$.

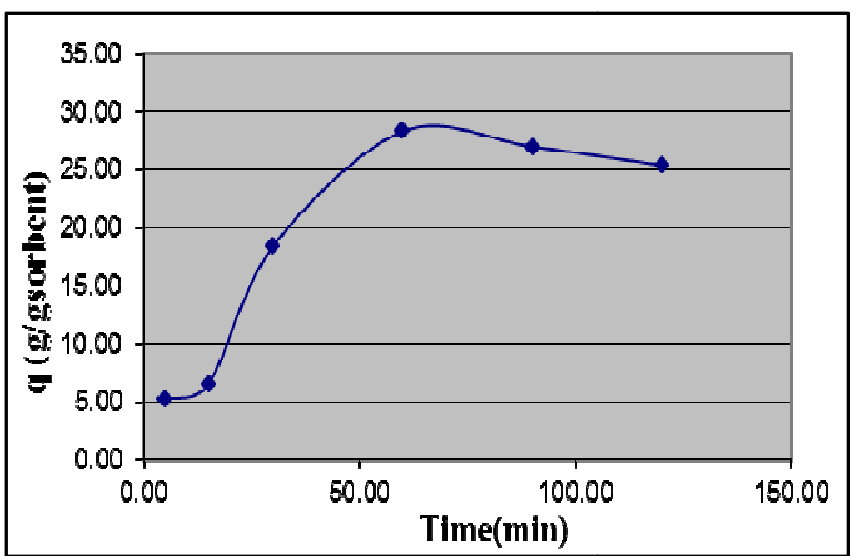

Figure (2). Effect of sorption time on the adsorption capacity of oil onto Nano-AC. (Dosage of material $=1 \mathrm{~g}$, oil film thickness $=5 \mathrm{~mm}$ oil slick, temperature $=25^{\circ} \mathrm{C}$, agitation speed $=105 \mathrm{rpm}$ ).

\subsubsection{Kinetic Modeling of the Oil Adsorption Process onto Nano-Activated Carbon}

Adsorption is physiochemical process that involves the mass transfer of a solute (adsorbate) from the liquid phase to the adsorbent surface. The study of adsorption dynamics describes the solute uptake rate and evidently this rate controls the residence time of adsorbate uptake at the solid-solution interface [15]. Therefore, a study of process kinetics is desirable as it provides information about the mechanism of adsorption, which is important for efficiency of the process. The study of adsorption kinetics is the main factor for designing an appropriate adsorption system and quantifying the changes in adsorption with time requires that an appropriate kinetic model is used [16]. Four kinetic models, pseudo first-order, pseudo second-order, Elovich, and intraparticle diffusion kinetic models were selected in this study to determine their applicability to describe the oil sorption process. The conformity between the experimental data and the model predicted values was expressed by their correlation coefficients $\left(\mathrm{R}^{2}\right.$ values close or equal to 1$)$. A relatively high $\mathrm{R}^{2}$ value indicates that the model successfully describes the kinetics of the adsorption [16].

The pseudo first-order kinetic model has been widely used to predict sorption kinetics. The model was presented by Lagergren [17]. The Lagergren's first-order reaction model is expressed as follow by Yalcin et al.:

$$
\mathrm{dq}_{\mathrm{t}} / \mathrm{dt}=\mathrm{k}_{1}\left(\mathrm{q}_{\mathrm{e}}-\mathrm{q}_{\mathrm{t}}\right)
$$

Where $\mathrm{q}_{\mathrm{e}}$ and $\mathrm{q}_{\mathrm{t}}$ are the amounts of oil $(\mathrm{g} / \mathrm{g})$ adsorbed on the adsorbent at equilibrium, and at time $t$, respectively, and $K_{1}$ is the first-order reaction rate constant $\left(\mathrm{min}^{-1}\right)$. Integrating and applying the boundary conditions, $\mathrm{t}=0$ and $\mathrm{q}_{\mathrm{t}}=0$ to $\mathrm{t}=\mathrm{t}$ and $\mathrm{q}_{\mathrm{t}}$ $=q_{t}$, Eq. (1) takes the form of Eq. (2).

$$
\operatorname{Ln}\left(\mathrm{q}_{\mathrm{e}}-\mathrm{q}_{\mathrm{t}}\right)=\operatorname{Ln}\left(\mathrm{q}_{\mathrm{e}}\right)-\mathrm{k}_{1} \mathrm{t}
$$

The values of $\operatorname{Ln}\left(q_{e}-q_{t}\right)$ were linearly correlated with $t$. The values of $\mathrm{K}_{1}$ and $\mathrm{q}_{\mathrm{e}}$ were determined from the slope and intercept of the linear plots $\operatorname{Ln}\left(\mathrm{q}_{\mathrm{e}}-\mathrm{q}_{\mathrm{t}}\right)$ against $\mathrm{t}$, respectively for the adsorption of oil using the prepared Nano-activated carbon and are listed in table (2) along with the corresponding correlation coefficient, $\mathrm{R}^{2}$. Figure (3) illustrates the linear plot of pseudo first-order equation. The correlation coefficient for the first-order model fitting is low $\left(\mathrm{R}^{2}=0.809\right)$. Also, the estimated value of $\mathrm{q}_{\mathrm{e}}$ calculated from the equation differed from the experimental value, table (2). Therefore, it can be inferred that the first-order model does not show good compliance with the experimental data.

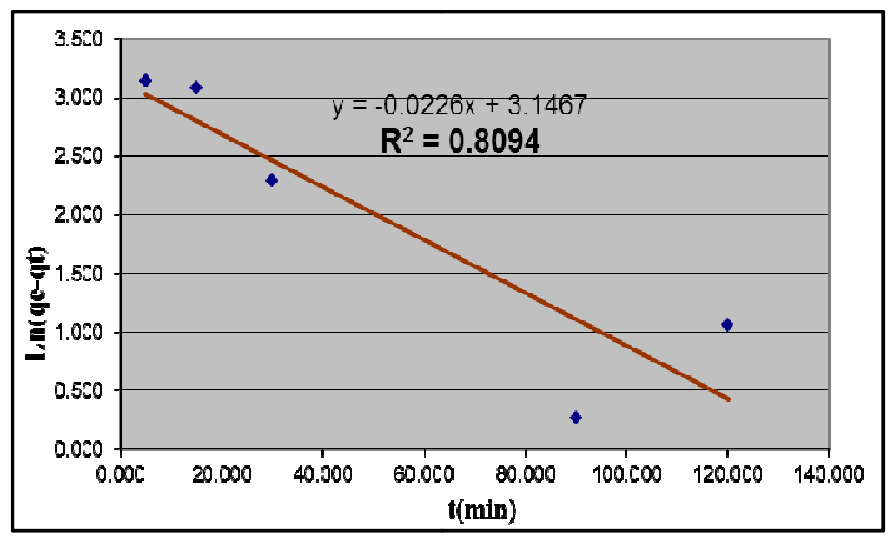

Figure (3). First-order plot for the adsorption of oil onto Nano-activated carbon.

The pseudo second-order rate model based on the sorption equilibrium capacity may be expressed in the following form [18]:

$$
\mathrm{dq}_{\mathrm{t}} / \mathrm{dt}=\mathrm{k}_{2}\left(\mathrm{q}_{\mathrm{e}}-\mathrm{q}_{\mathrm{t}}\right)^{2}
$$

Where $\mathrm{k}_{2}$ is the rate constant of the pseudo second-order sorption (g/g.min). Integrating and applying boundary conditions $\mathrm{t}=0$ and $\mathrm{q}_{\mathrm{t}}=0$ to $\mathrm{t}=\mathrm{t}$ and $\mathrm{q}_{\mathrm{t}}=\mathrm{q}_{\mathrm{t}}$, Eq. (3) becomes:

$$
1 /\left(\mathrm{q}_{\mathrm{e}}-\mathrm{q}_{\mathrm{t}}\right)=1 / \mathrm{q}_{\mathrm{e}}+\mathrm{k}_{2} \mathrm{t}
$$

This is the integrated rate law for a pseudo second-order reaction. Eq. (4) can be rearranged to obtain the linear form in Eq. (5).

$$
\mathrm{t} / \mathrm{q}_{\mathrm{t}}=1 / \mathrm{k}_{2} \mathrm{q}_{\mathrm{e}}^{2}+1 / \mathrm{q}_{\mathrm{e}}(\mathrm{t})
$$

The values of $\mathrm{k}_{2}$ and $\mathrm{q}_{\mathrm{e}}$ were determined from the intercept and slope of the linear plots of $\operatorname{Ln}\left(q_{e}-q_{t}\right)$ against $t$, respectively for the adsorption process of oil using the prepared Nano-activated carbon and are listed in table (2) along with the corresponding correlation coefficient, $\mathrm{R}^{2}$. Also the estimated values of $\mathrm{q}_{\mathrm{e}}$ calculated from Eq. (5) are listed in table (2). Figure (4) illustrates the linear plot of pseudo second-order equation. The correlation coefficient, $\mathrm{R}^{2}$ for the pseudo second-order adsorption model have the highest value $\left(\mathrm{R}^{2}=0.9923\right)$, indicating that the oil adsorption process is predominated by the pseudo second-order adsorption mechanism. Additionally, the calculated value of $\mathrm{q}_{\mathrm{e}}$ that obtained from the slope of the linear plot has been compared with that obtained from the experimental data; the two values of $\mathrm{q}_{\mathrm{e}}$ are closer to each other than in case of the pseudo 
first-order model. Thus, the second-order rate expression fits the data most satisfactorily.

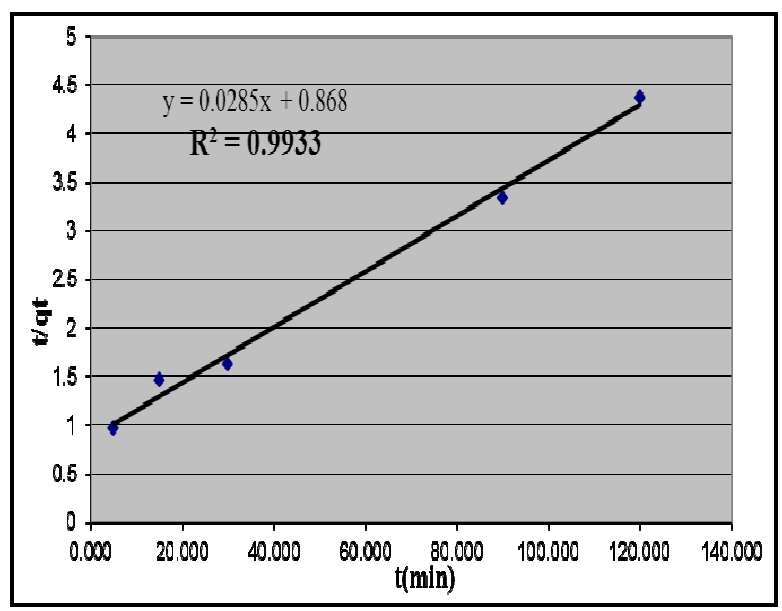

Figure (4). Second-order plot for the adsorption of oil onto Nano-activated carbon.

The simple Elovich model is one of the most useful models for describing the kinetics of chemisorption. It is based on a kinetic principle assuming that the adsorption sites increase exponentially with adsorption, which implies a multilayer adsorption [19]. A plot of $\mathrm{q}_{\mathrm{t}}$ versus $\mathrm{Ln}(\mathrm{t})$ should present $\mathrm{a}$ linear relationship for the applicability of simple Elovich kinetic. Figure (5) illustrates a plot of $\mathrm{q}_{\mathrm{t}}$ against $\ln (\mathrm{t})$ for the sorption of oil onto the prepared Nano-activated carbon. From the slope and intercept of linearization of the simple Elovich equation, the estimated Elovich equation parameters are tabulated in table (2). The value of $\beta$ is indicative of the number of sites available for adsorption, whereas $\alpha$ is the adsorption quantity [20]. This value is helpful in understanding the adsorption behavior of the first step. Also, on the basis of this table, it was declared that the Elovich equation does not fit the experimental data well, where its correlation coefficient value is comparatively low $\left(\mathrm{R}^{2}=\right.$ 0.9082). This suggested that the studied sorption system may take place through physical sorption between the sorbent and the sorbate.

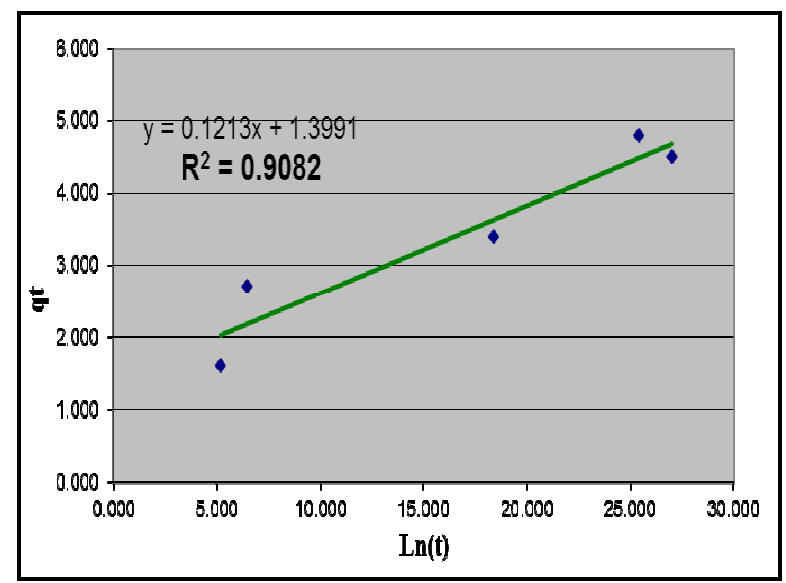

Figure (5). Simple Elovich plot for the adsorption of oil onto Nano-activated carbon.
The sorption of any adsorbate from an aqueous phase to a solid phase is a multistep process involving three consecutive steps [21]:

1. The transport of sorbate from bulk solution to outer surface of the sorbent by molecular diffusion, known as external or film diffusion.

2. Internal diffusion, the transport of sorbate from the particles surface into interior sites.

3. The sorption of the solute particles from the active sites into the interior surface of the pores, pore diffusion or intraparticle diffusion.

The overall rate of the sorption process will be controlled by the slowest, the rate limiting step. If the experiment is a batch system with rapid stirring, there is possibility that intraparticle diffusion is the rate-determining step [21]. The nature of the rate-limiting step in a system can be determined from the properties of the solute and sorbent [21]. In adsorption systems where there is the possibility of intraparticle diffusion being the rate-limiting step, the intraparticle diffusion approach described by Weber and Morris is used [22]. The rate constants, for intraparticle diffusion $\left(\mathrm{K}_{\mathrm{i}}\right)$ are determined using equation given by Weber and Morris [28]. This equation can be described in the form of Eq. (6).

$$
\mathrm{q}_{\mathrm{t}}=\mathrm{I}+\mathrm{k}_{\mathrm{id}} \mathrm{t}^{1 / 2}
$$

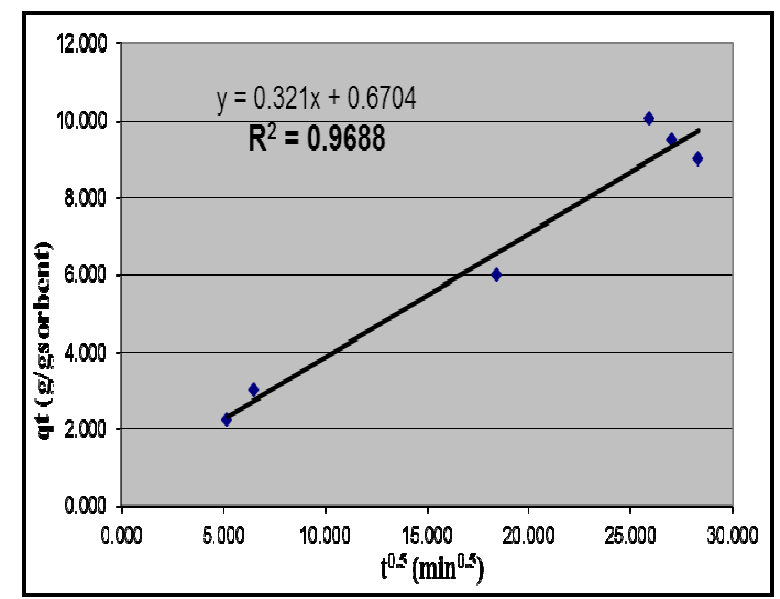

Figure (6). Intraparticle diffusion plot for the adsorption of oil onto Nano-activated carbon.

Values of I give an idea about the thickness of the boundary layer. If the intraparticle diffusion occurs, then $\mathrm{q}_{\mathrm{t}}$ versus $\mathrm{t}^{1 / 2}$ will be linear and if the plot passes through the origin, then the rate limiting process is only due to the intraparticle diffusion. Otherwise, some other mechanisms along with intraparticle diffusion are also involved [21]. Figure (6) illustrates a plot of $\mathrm{q}_{\mathrm{t}}$ versus $\mathrm{t}^{1 / 2}$ for the sorption of oil onto prepared Nano-activated carbon. The $\mathrm{k}_{\mathrm{id}}$ is the slope of the straight line plot and the value of $\mathrm{I}$ is the intercept. The values of constants $\mathrm{k}_{\mathrm{id}}$ and I for interaparticle diffusion kinetic are given in table (2) as well as the corresponding correlation coefficient, $\mathrm{R}^{2}$. The correlation coefficient, $\mathrm{R}^{2}$ for this diffusion model was 0.9688 , suggesting that the adsorption process can be followed by intraparticle diffusion model. Furthermore, the plot did not pass through the origin, such a deviation of the line from the 
origin is an indicative of some degree of boundary layer control and this further showed that the intraparticle diffusion was not the only rate-limiting step, but other processes might control the rate of adsorption.

Finally, comparison of the three models, pseudo first-order, pseudo second-order, and Elovich reveals that the $\mathrm{R}^{2}$ for the equations showed that the results can be well represented by the pseudo second-order model. The suggested main adsorption mechanism for oil sorption process onto Nano-activated carbon is probably physico-sorption, involving van der Walls forces between the sorbate and sorbent [14]. Besides, the high value of the correlation coefficient, $\mathrm{R}^{2}$ for the diffusion model suggests that the adsorption process can be followed by the intraparticle diffusion model. The four correlation coefficients, $\mathrm{R}^{2}$ for the applied adsorption kinetic models for the adsorption of oil onto Nano-activated carbon are summarized in table (3).

\subsection{Equilibrium Behavior of Oil Adsorption Process onto Nano-Activated Carbon}

In order to determine the equilibrium behavior of the oil adsorption process onto the prepared nano-activated carbon the influence of the activated carbon dosage at the equilibrium was examined.

Table (2). Kinetic parameters for adsorption of oil onto prepared Nano-activated carbon.

\begin{tabular}{lll}
\hline Kinetic model & Parameters & Value \\
\hline Pseudo first-order & $\left(\mathrm{q}_{\mathrm{e}}\right)_{\text {cal }}(\mathrm{g} / \mathrm{g})$ & 23.26 \\
& $\left(\mathrm{q}_{\mathrm{e}}\right)_{\exp }(\mathrm{g} / \mathrm{g})$ & 28.31 \\
& $\mathrm{k}_{1}\left(\mathrm{~min}^{-1}\right)$ & 0.0226 \\
& $\mathrm{R}^{2}$ & 0.809 \\
Pseudo second-order & $\left(\mathrm{q}_{\mathrm{e}}\right)_{\text {cal }}(\mathrm{g} / \mathrm{g})$ & 25.81 \\
& $\left(\mathrm{q}_{\mathrm{e}}\right)_{\exp }(\mathrm{g} / \mathrm{g})$ & 28.31 \\
& $\mathrm{k}_{2}(\mathrm{~g} / \mathrm{g} \cdot \mathrm{min})$ & $1.74 \times 10^{-3}$ \\
& $\mathrm{R}^{2}$ & 0.9933 \\
Elovich model & $\alpha(\mathrm{g} / \mathrm{g} \cdot \mathrm{min})$ & 1.3991 \\
& $\beta(\mathrm{g} / \mathrm{g})$ & 0.1213 \\
& $\mathrm{R}^{2}$ & 0.908 \\
Intraparticle diffusion model & $\mathrm{k}_{\text {id }}(\mathrm{g} / \mathrm{g} \cdot \mathrm{min})$ & 0.321 \\
& $\mathrm{I}$ & 0.6704 \\
& $\mathrm{R}^{2}$ & 0.9688 \\
\hline
\end{tabular}

Table (3). $R^{2}$ values for oil adsorption with the different studied adsorption kinetics.

\begin{tabular}{lllll}
\hline $\begin{array}{l}\text { Kinetic } \\
\text { model }\end{array}$ & $\begin{array}{l}\text { Pseudo } \\
\text { first-order }\end{array}$ & $\begin{array}{l}\text { Pseudo } \\
\text { second-order }\end{array}$ & Elovich & $\begin{array}{l}\text { Intraparticle } \\
\text { diffusion }\end{array}$ \\
\hline $\mathrm{R}^{2}$ & 0.809 & 0.9933 & 0.908 & 0.9688 \\
\hline
\end{tabular}

\subsubsection{Effect of Adsorbent Dosage}

Adsorbent dosage is representing an important parameter due to its strong effect on the capacity of an adsorbent at given initial concentration of the adsorbate [14]. The effect of the adsorbent dosage on the adsorption capacity onto the synthetic Nano-activated carbon was investigated at figures (7). It was indicated that the increase in the adsorbent dosage from 0.1 to $20 \mathrm{~g}$ decreases the oil uptake capacity from 82.01 to $1.52 \mathrm{~g}$ gas $\mathrm{oil} / \mathrm{g}$. Many suggested reasons can contribute to this behavior.
The most important reason is that the adsorption sites of the material remain unsaturated during the oil adsorption reaction [14]. This decrease in oil adsorption capacity with the increase in the adsorbent dosage is mainly attributed to the non-saturation of the adsorption sites present at adsorbent material during the adsorption process [14]. Another reason may be due to the particle interactive behavior, such as aggregation, resulting from the high adsorbent dose. Such aggregation would lead to a decrease in the total surface area of the adsorbent material and an increase in the oil diffusion path length [14].

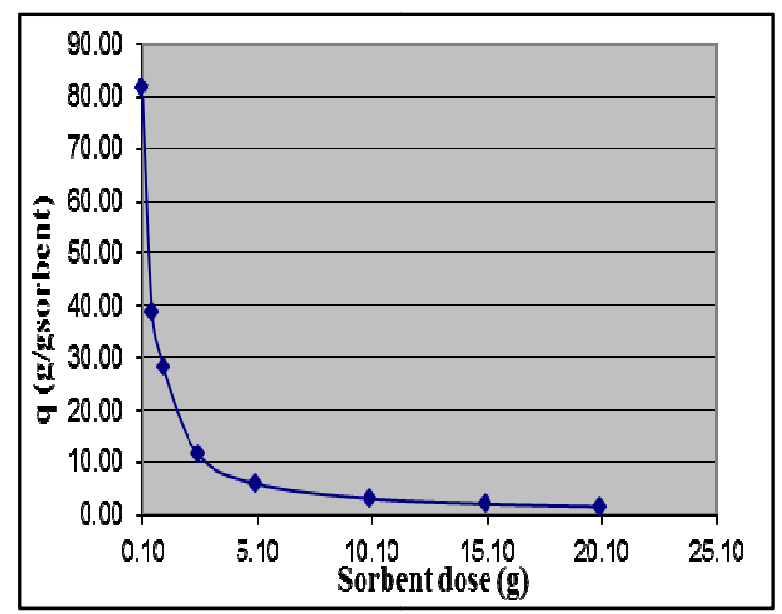

Figure (7). Effect of sorbent weight on the adsorption capacity of oil onto Nano-AC.(Sorption time $=60 \mathrm{~min}$, oil film thickness $=5 \mathrm{~mm}$ oil slick, temperature $=25^{\circ} \mathrm{C}$, agitation speed $\left.=105 \mathrm{rpm}\right)$.

\subsubsection{Equilibrium Modeling of the Oil Adsorption Process onto Nano-Activated Carbon}

In order to optimize the design of an adsorption system to remove the oil spill using prepared Nano-activated carbon, it is important to establish the most appropriate correlations for describing the equilibrium data. Besides, the study of the adsorption kinetics is the main factor for designing an appropriate adsorption system and quantifying the changes in adsorption with time requires that an appropriate kinetic model will be determined. In this study, both equilibrium study and adsorption kinetics data were modeled for oil spill cleanup using the prepared Nano-activated carbon.

Equilibrium data, commonly known as adsorption isotherms, are basic requirements for the design of adsorption systems [16]. The adsorption isotherm indicates how the adsorbate molecules are distributed between the liquid phase and the solid phase when the adsorption process reaches an equilibrium state [17]. The analysis of the isotherms data by fitting them to different isotherm models is an important step to find a suitable model that can be used for design purposes. Adsorption isotherm is basically important to describe how adsorbates interact with adsorbents, and is critical in optimizing the use of adsorbents [17]. Isotherm expresses the relation between the mass of oil adsorbed at constant temperature per unit mass of the adsorbent and the liquid phase oil concentration. Adsorption isotherm study was carried out on four isotherm models: the Langmuir, Freundlich, 
Temkin, and Dubinin-Radushkevich (D-R) isotherm models. The applicability of the isotherm equation to the adsorption study done was compared by judging the correlation coefficients, $\mathrm{R}^{2}$ [18].

The Langmuir isotherm is based on the theoretical principle that suggest only monolayer adsorption onto a surface of the adsorbent material containing a finite number of adsorption sites of uniform strategies of adsorption with no transmigration of adsorbate in the plane of surface [18]. Also, it represents the equilibrium distribution of oil molecules between the solid and liquid phases. The basic assumption of the Langmuir adsorption process is the formation of a monolayer and after that no further adsorption takes place [18] When $\mathrm{C}_{\mathrm{e}} / \mathrm{q}_{\mathrm{e}}$ was plotted against $\mathrm{C}_{\mathrm{e}}$, a straight line with the slope of $1 / \mathrm{q}_{\mathrm{m}}$ and intercept of $1 / \mathrm{q}_{\mathrm{m}} \mathrm{K}_{\mathrm{L}}$ was obtained [18]. The values of Langmuir constants $\mathrm{q}_{\mathrm{m}}$ and $\mathrm{K}_{\mathrm{L}}$ are listed in table (4). The essential characteristics of the Langmuir isotherm can be expressed in terms of a dimensionless equilibrium parameter. The parameter is defined by [20]:

$$
\mathrm{R}_{\mathrm{L}}=1 /\left(1+\mathrm{K}_{\mathrm{L}} \mathrm{C}_{\mathrm{o}}\right)
$$

Where $\mathrm{K}_{\mathrm{L}}$ is the Langmuir constant and $\mathrm{C}_{\mathrm{o}}$ is the initial oil concentration. The value of $\mathrm{R}_{\mathrm{L}}$ indicates the type of the isotherm to be either unfavorable $\left(R_{L}>1\right)$, linear $\left(R_{L}=1\right)$, favorable $\left(0<\mathrm{R}_{\mathrm{L}}<1\right)$, or irreversible $\left(\mathrm{R}_{\mathrm{L}}=0\right)$ [14]. The calculated values of $\mathrm{R}_{\mathrm{L}}$ for the different studied initial oil concentrations observed to be in the range $0-1$, indicating that the adsorption is a favorable process for the prepared Nano-activated carbon as adsorbent material. Figure (8) illustrates the linear plot of Langmuir equation. The comparatively low value of correlation coefficient $\mathrm{R}^{2}(0.92)$ for the Langmuir isotherm showed that the adsorption of oil onto the used prepared Nano-activated carbon adsorbent may be described by the Langmuir isotherm.

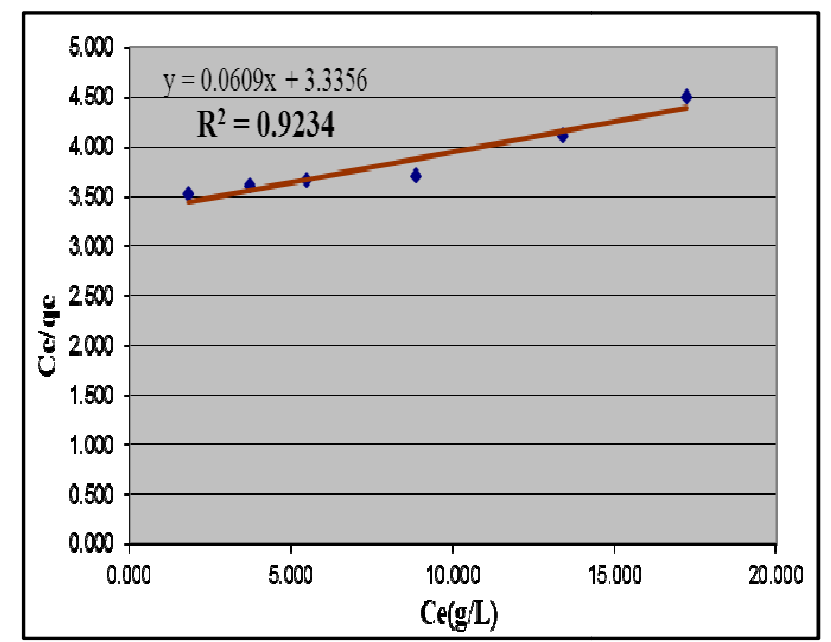

Figure (8). Langmuir isotherm plot for adsorption of oil onto Nano-activated carbon.

The Freundlich isotherm is a widely used equilibrium model but provides no information on the monolayer sorption capacity, in contrast to the Langmuir model [20]. The Freundlich isotherm model assumes neither homogeneous site energies nor limited levels of sorption; it is an indicator of the extent of heterogeneity of the adsorbent surface [20]. The Freundlich adsorption model stipulates that the ratio of solute adsorbed to the solute concentration is a function of the solution [18]. The Freundlich model is the earliest known empirical equation and has been shown to be consistent with the exponential distribution of active centers, which is characteristic of heterogeneous surfaces [20]. A plot of $\ln (\mathrm{qe})$ versus $\ln \left(\mathrm{C}_{\mathrm{e}}\right)$, where the values of $\mathrm{K}_{\mathrm{F}}$ and $1 / \mathrm{n}_{\mathrm{f}}$ are determined from the intercept and slope of the linear regressions are listed in table (4) along with the corresponding correlation coefficient, $\mathrm{R}^{2}$. The intercept of the plotted line, $\mathrm{K}_{\mathrm{f}}$ is roughly an indicator of adsorption capacity and the slope, $\mathrm{n}_{\mathrm{f}}$, is an indicator of adsorption effectiveness [20]. Figure (9) illustrates the linear plot of Freundlich equation. The correlation coefficient is $\left(\mathrm{R}^{2}=0.9996\right)$ which expressing an agreement with the experimental data of adsorption of oil onto the prepared Nano-activated carbon, it was demonstrated that the removal of gas oil with Nano-activated carbon obeyed the Freundlich isotherm. From the estimated value of $n_{f}$, it was found that $\mathrm{n}_{\mathrm{f}}>1\left(\mathrm{n}_{\mathrm{f}}=1.089\right)$, dedicated favorable adsorption for oil molecules with the prepared Nano-activated carbon [21]. This is in great agreement with the findings regarding to $\mathrm{R}_{\mathrm{L}}$ values. The magnitude of Freundlich constant indicates easy uptake of oil from the aqueous solution [14]. As the Freundlich isotherm showed the best fit, this suggested that some heterogeneity on the surfaces or pores of the prepared Nano-activated carbon played a role in the oil sorption [20].

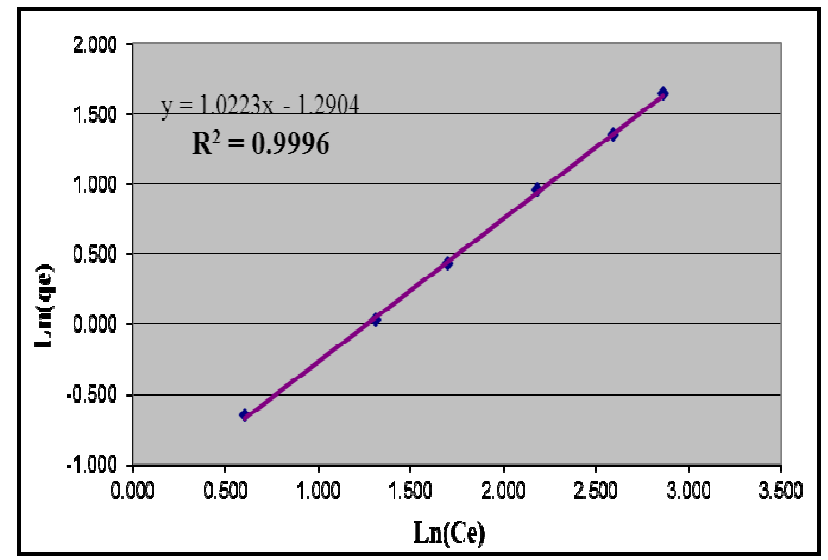

Figure (9). Freundlich isotherm plot for adsorption of oil onto Nano-activated carbon.

Temkin considered the effects of indirect adsorbent/adsorbate interactions on the adsorption isotherm [18]. The heat of adsorption of all the molecules in the layer would decrease linearly with coverage due to adsorbent-adsorbate interactions, and that the adsorption is characterized by a uniform distribution of the binding energies, up to some maximum binding energy [22]. A plot of $\mathrm{q}_{\mathrm{e}}$ versus $\ln \left(\mathrm{C}_{\mathrm{e}}\right)$ enables the determination of isotherm constants $\mathrm{B}$ and $\mathrm{K}_{\mathrm{T}}$ from the slope and intercept, respectively. When the intercept value is larger, this means that the adsorbent/adsorbate interaction is also larger [23]. The parameters of Temkin model as well as the corresponding 
correlation coefficient, $\mathrm{R}^{2}$ are listed in table (4). Figure (10) illustrates the linear plot of Temkin equation. The correlation coefficient is $\left(\mathrm{R}^{2}=0.919\right)$ showing the relatively poorest fit to the experimental adsorption equilibrium data.

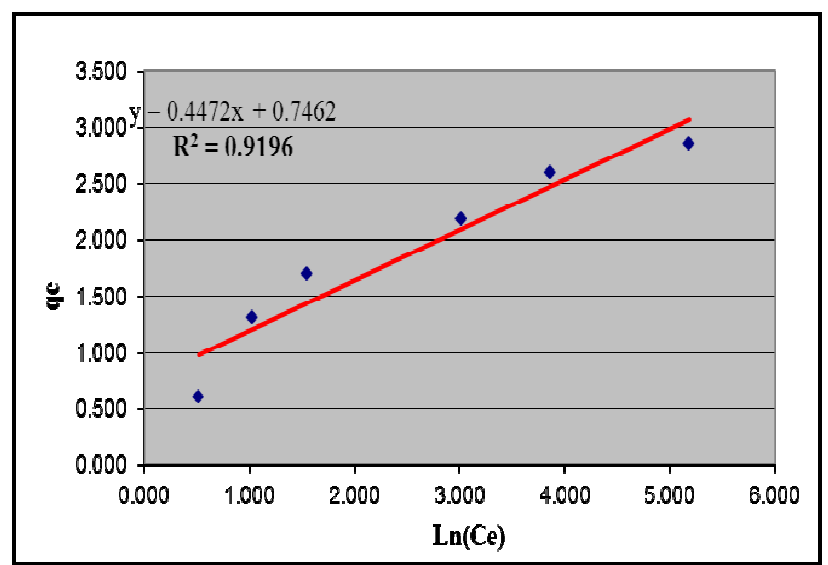

Figure (10). Temkin isotherm plot for adsorption of oil onto Nano-activated carbon.

Langmuir, Freundlich, and Temkin isotherms are insufficient to explain the physical and chemical characteristics of adsorption. The D-R isotherm is commonly used to describe the sorption isotherms of single solute systems [20]. The D-R isotherm, apart from being an analogue of the Langmuir isotherm, is more general than the Langmuir isotherm because it rejects the homogeneous surface or constant adsorption potential [21]. The constant K' gives the mean free energy of sorption per molecule of the sorbate (E) when it is transferred to the surface of the solid from infinity in the solution. This energy gives information about the physical and chemical features of the sorption process and can be computed with the following relationship:

$$
\mathrm{E}=\left(2 \mathrm{~K}^{\prime}\right)^{-0.5}
$$

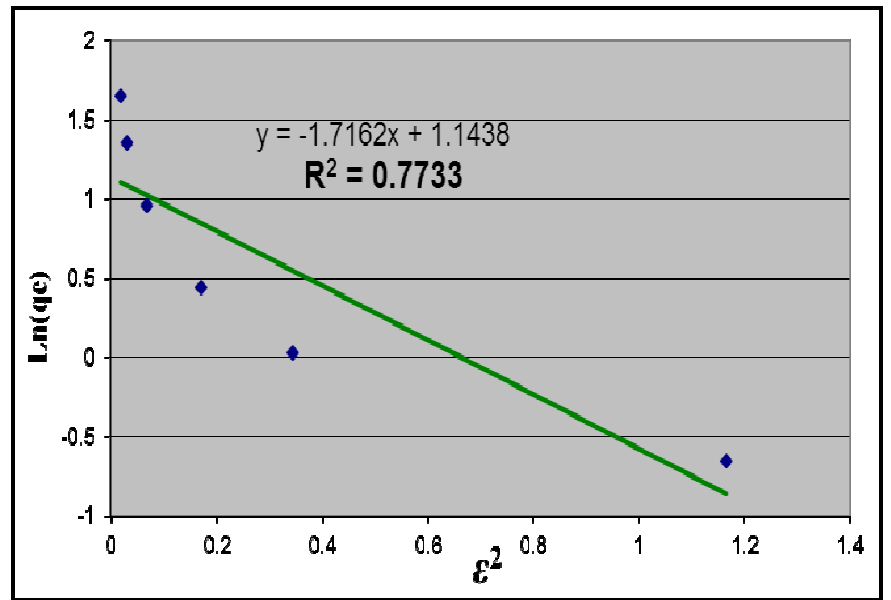

Figure (11). $D-R$ isotherm plot for adsorption of oil onto Nano-activated carbon.

This energy gives information about the sorption mechanism; it is perceived as the amount of energy required to transfer $1 \mathrm{~mol}$ of the adsorbate molecule from infinity in the bulk of the solution to the site of sorption [20]. The D-R isotherm model was applied to the equilibrium data obtained from the empirical studies for oil removal onto the prepared Nano-activated carbon to determine the nature of the sorption process (physical or chemical). A plot of $\operatorname{Ln}\left(\mathrm{q}_{\mathrm{e}}\right)$ against $\varepsilon^{2}$ is given in figure (11). The $\mathrm{D}-\mathrm{R}$ plot yields a straight line with the correlation coefficient, $\mathrm{R}^{2}$ value equal to 0.77333 , and this indicates that the $\mathrm{D}-\mathrm{R}$ models less fits the experimental data in comparison with the Langmuir, Freundlich, and Temkin isotherm models. The model corresponding parameters are listed in table (4) along with its corresponding correlation coefficient, $\mathrm{R}^{2}$. The calculated adsorption energy $(\mathrm{E}<8 \mathrm{~kJ} / \mathrm{mol})$ indicates that the oil sorption process could be considered physisorptional in nature.

Table (4). Isotherm parameters for adsorption of oil onto prepared Nano-activated carbon.

\begin{tabular}{lll}
\hline Isotherm & Parameter & Value \\
\hline \multirow{3}{*}{ Langmuir } & $\mathrm{q}_{\mathrm{m}}(\mathrm{g} / \mathrm{g})$ & 16.420 \\
& $\mathrm{~K}_{\mathrm{L}}(\mathrm{L} / \mathrm{g})$ & 0.0183 \\
& $\mathrm{R}^{2}$ & 0.923 \\
& $\mathrm{~K}_{\mathrm{f}}\left(\mathrm{g} / \mathrm{g}(\mathrm{L} / \mathrm{g})^{1 / \mathrm{n}}\right)$ & 0.2751 \\
Freundlich & $\mathrm{nf}$ & 1.08 \\
& $\mathrm{R}^{2}$ & 0.9996 \\
& $\mathrm{~K}_{\mathrm{T}}(\mathrm{L} / \mathrm{g})$ & 5.305 \\
Temkin & $\mathrm{B}(\mathrm{J} / \mathrm{mol})$ & 0.4472 \\
& $\mathrm{R}^{2}$ & 0.91 \\
& $\mathrm{~K}^{\prime}\left(\mathrm{mol}{ }^{2} / \mathrm{kJ}^{2}\right)$ & 1.7162 \\
& $\mathrm{~V}_{\mathrm{m}}^{\prime}(\mathrm{g} / \mathrm{g})$ & 3.1387 \\
& $\mathrm{R}^{2}$ & 0.773 \\
\hline \multirow{2}{*}{ Dubinin-Radushkevich } & $\mathrm{E}^{2}(\mathrm{~kJ} / \mathrm{mol})$ & 0.539 \\
\hline
\end{tabular}

\section{Conclusion}

Nano-activated carbon was successfully prepared from water hyacinth. The SEM imaging confirmed its preparation in nan-size. The experimental results evident that nano-activated carbon has high oil sorption capacity reached to $0.2 \mathrm{mg} / \mathrm{g}$ within $60 \mathrm{~min}$. The equilibrium isotherm models applicability of the oil sorption process onto nano-activated carbon obeyed both Freundlich and Langmuir isotherms, which suggests that the oil sorption takes place onto Nano-activated carbon as mono-layer coverage with some heterogeneity oil sorption process on the surfaces or pores of the prepared Nano-activated carbon. The kinetic study of oil sorption onto the activated carbon surface was performed based on pseudo first-order, pseudo second-order, and intraparticle diffusion models. The data indicate that the adsorption kinetics follow the pseudo second-order model with intraparticle diffusion as one of the rate determining steps. The suggested main adsorption mechanism for oil sorption process onto Nano-activated carbon is probably physico-sorption involving van der Waals forces between the sorbent material and the oil sorbate. 


\section{References}

[1] Ghazi, J., Sultan, S., and Lihaibi, A.I., "Hydrocarbon Distributions in Sediments of the Open Area of the Arabian Gulf Following the 1991 Gulf war oil", Marine Pollution Bulletin Journal, Vol. 34, PP. 941-948, 1997.

[2] Page, C.A., Bonner, J.S., McDonald, T.J., and Autenrieth, R.L., "Behavior of a Chemically Dispersed Oil Wetland Environment”, Water Res, Vol. 36, PP. 3821-3833, 2002.

[3] Teas, C., Kalligeros, S., Zanikos, F., Stoumas, S., Lois, E., and Anastopoulos, G., "Investigation of the Efectiveness of Absorbent Materials in Oil Spills Cleanup", Desalination, N140, PP. 259-264, 2001.

[4] Madkour, R. A., International Journal of Energy and Environment, Vol. 2, N1, 2008.

[5] Wardley-Smith J., "The Control of Oil Pollution", Graham and Trotman Publication, London, 1983.

[6] National Research Council (NRC), "Using Oil Spill Dispersants on the Sea", National Academy Press, Washington, DC, 1989.

[7] http://www.epa.gov/oilspill/sorbents.htm.

[8] Riazi, M.R., and AL-Enezi, G.A., "Modeling of the Rate of Oil Spill Disappearance from Seawater for Kuwaiti Crude and its Products", Chemical Engineering Journal, Vol. 73, N2, PP. 161-172, 1999.

[9] Adamson, A.W., "Physical Chemistry of Surfaces", (5th edition), Wiley Journal, New York, PP. 662, 1990.

[10] Ali N., Chaudhary B.L., and Khandelwal S.K., "Better Use of Water Hyacinth for Fuel, Manure and Pollution Free Environment", Indian Journal Environ, 2004.

[11] Bansal, R.C., Vastola, F.J., and Walker, P.L., "Carbon journal”, Vol. 9, N185, 1971.

[12] Toles, C.A., Marshall, W.E., and Johns, M.M., "Granular Activated Carbons from Nutshells for the Uptake of Metals and Organic Compounds", Vol. 35, N9, PP. 1407-1414, 1997.

[13] Elkady, M.F., Hussein, M.M., and Salama, M.M., "Synthesis and characterization of nano-activated carbon from el maghara coal, Sinai, Egypt to be utilized for wastewater Purification", American Journal of Applied Chemistry, Vol.3, PP. 1-7, 2015.
[14] Elkady, M.F., Hussein, M.M., and Abou-rady, R., "Extraction of Nano-activated Carbon from Water Hyacinth as Adsorbent Material for Oil Spills Treatment", Batholia Journal, Vol. 44, (2014), 115-138.

[15] Abd El-Latif, M.M., Amal, M. Ibrahim, and El-Kady, M.F., "Adsorption Equilibrium, Kinetics and Thermodynamics of Methylene Blue from Aqueous Solutions Using Biopolymer Oak Sawdust Composite", Journal of American Science, Vol. 6, N6, PP. 267-283, 2010.

[16] Abd El-Latif, M.M., and Elkady, M.F., "Kinetic study and thermodynamic behavior for removing cesium, cobalt and nickel ions from aqueous solution using nano-zirconium vanadate ion exchanger", Desalination, Vol. 271, PP. 41-54, 2011.

[17] Jianlong, W., Xinmin, Z., Decai, D., and Ding, Z., "Bioadsorption of Lead (II) from Aqueous Solution by Fungal Biomass of Aspergillus niger", Journal of Biotechnology, Vol. 87, 2001.

[18] Elkady, M.F., EL-Sayed, E.M., Farag, H.A. and Zaatout, A.A., "Assessment of novel synthetized nano-zirconium tungstovanadate as cation exchanger for Lead ion decontamination", Journal of Nanomaterials, PP. 1-11, 2014.

[19] Ozacar, M., and Sengil, I.A., Process Biochemistry Journal, PP. 303-494, 2005.

[20] Mohy-Eldin, M.S., El-Kady, M.F., Abu-Saied, M.A., Adel-Rahman, A.M., Soliman, E.A., El-Zatahry, A.A., and Youssef, M.E., "Removal of Cadmium Ions from Synthetic Aqueous Solutions with a Novel Nano Sulfonated Poly (Glycidyl Methacrylate) Cation Exchanger: Kinetic and Equilibrium Studies", Journal of Applied polymer science, Vol. 6, PP. 280-292, 2010.

[21] Shokry, H.H., El-Kady, M.F., El-Shazly, A., and Bamufleh, H., "Formulation of Synthesized Zinc Oxide Nano-Powder into Hybrid Beads for Dye Separation", Journal of Nanomaterials, PP. 1-4, 2014.

[22] Weber, W.J., and Morris, J.C., "Kinetics of Adsorption on Carbon from Solution", Journal of the Sanitary Engineering Division, American Society of Civil Engineering, Vol. 89, PP. 31-60, 1963.

[23] Tan, L.A.W., Ahmed, A.L., and Hameed, B.H., "Adsorption of Basic Dye Using Activated Carbon Prepared from Oil Palm Shell: Batch and Fixed Bed Studies", Desalination Journal, Vol. 25, PP. 13-28, 2008. 